\title{
COOPERATIVE HUNTING ROLES AMONG TAÏ CHIMPANZEES
}

\author{
Christophe Boesch \\ Max Planck Institute for Evolutionary Anthropology \\ Leipzig, Germany
}

\begin{abstract}
All known chimpanzee populations have been observed to hunt small mammals for meat. Detailed observations have shown, however, that hunting strategies differ considerably between populations, with some merely collecting prey that happens to pass by while others hunt in coordinated groups to chase fast-moving prey. Of all known populations, Taï chimpanzees exhibit the highest level of cooperation when hunting. Some of the group hunting roles require elaborate coordination with other hunters as well as precise anticipation of the movements of the prey. The meat-sharing rules observed in this community guarantee the largest share of the meat to hunters who perform the most important roles leading to a capture. The learning time of such hunting roles is sometimes especially long. Taï chimpanzee males begin hunting monkeys at about age 10. The hunters' progress in learning the more sophisticated hunting roles is clearly correlated with age; only after 20 years of practice are they able to perform them reliably. This lengthy learning period has also been shown in some hunter-gatherer societies and confirms the special challenge that hunting represents.
\end{abstract}

KEY WORDS: Chimpanzee; Hunting; Cooperation; Sharing

Cooperation has been presented as a central characteristic of many human societies through which individuals gain access to resources either that would not be available to them if they were on their own or that are shared

Received January 3, 2001; accepted May 10, 2001.

Address all correspondence to Christophe Boesch, Max Planck Institute for Evolutionary Anthropology, Inselstrasse 22, 04103 Leipzig, Germany. Email: boesch@eva.mpg.de

Copyright 2002 by Walter de Gruyter, Inc., New York

Human Nature, Vol. 13, No. 1, pp. 27-46.

$1045-6767 / 02 / \$ 1.00+.10$ 
with them (Foley 1989; Leakey 1981; Kaplan et al. 2000). However, it is unclear how much cooperation exists in other animal species and, when present, how this cooperation is performed. We should expect cooperation to occur within a population only if it brings some benefit to the individual investing in the common task.

When should individuals cooperate in hunting? Cooperation between individuals may have evolved via mutualism (Maynard Smith 1982), kin selection (Hamilton 1964), or reciprocity (Axelrod and Hamilton 1981; Trivers 1971). In mutualism, the participants in the interaction receive greater benefits than they do when acting alone, and understanding its evolution seems straightforward. In kin selection, the unequal benefit from a joint action accruing to the two participants is acceptable because of their close relatedness. In reciprocity, only one of the two participants gains at a time, and it is through repetitive interactions between them, and alternation of the gains, that the benefit can be distributed equally between the participants. Cheating is a constant threat to the evolution and maintenance of cooperation (Maynard Smith 1982): Individuals may try to profit from the action of others without themselves paying the cost. This has proved to be a major problem for, in theory, it is almost always better to cheat than to cooperate.

Few tests in animals of these models exist because of the difficulty in quantifying precisely the different gains of all possible strategies for each participant (Clements and Stephens 1995; Dugatkin 1997). Hunting by social animals sometimes involves the combined action of many individuals. These group actions enable larger prey to be subdued and participants to hunt more frequently than when alone (Kruuk 1972; Schaller 1972). Why is group hunting not the rule in social animals, and what do participants gain from group hunts? In hunting situations meat is often shared, and individuals who did not participate regularly try to gain access to it, thereby diminishing the benefit of the hunters. An understanding of the mechanisms and the benefit of cooperation requires, therefore, that benefits and costs be calculated for all participants for each hunt to sort out the payoff of the different strategies. Observations of the Gilgil baboons have nicely illustrated the dilemma (Strum 1981). As long as the major hunter in this group was the alpha male, hunts were regular, and other group members participating in the hunts were content with scraps they could recover on the ground (baboons do not share meat intentionally). Once this lead hunter lost his alpha position, the new alpha male stole all the captures he made. As a consequence, he refrained from hunting, as did the others, and hunting disappeared rapidly within this population.

Cooperative hunting has often been observed in social carnivores (lions: Cooper 1991; Packer et al. 1990, Schaller 1972, Stander 1992, Van Orsdol 1984; wild dogs: Creel and Creel 1995, Estes and Goddard 1967, Fanshawe 
and Fitzgibbon 1993; hyenas: Kruuk 1972, Mills 1990; wolves: Mech 1970). Individual food intake across hunt group sizes in some carnivore populations tended toward a U-shaped distribution, with one maximum for single hunters and sometimes a second maximum for the largest groups (Caro 1994; Packer et al. 1990). More recent studies have shown that individual lions do not all invest the same amount of energy in the hunt and may perform different roles (Scheel and Packer 1991; Stander 1992). Pack size, which has been used in most lion studies as a proxy for hunting group size, does not differentiate between hunters and non-hunters, and this is misleading: In Etosha, all females within a pack hunt (Stander 1992), whereas in the Serengeti the number of female cheaters increases with the ease of a hunt (Scheel and Packer 1991). Including the costs of hunting in the analysis can notably alter the payoff (Boesch 1994b; Creel and Creel 1995). Thus, the economics of cooperation, which depend on the prevailing conditions, will determine the number of individuals that will take part in the common action.

How do individuals cooperate? Cooperation has to be performed by at least two individuals, and how they perform the cooperative task will affect the outcomes. The performance may also be constrained by their cognitive capacities. A detailed description of the actions performed by the participants will provide important indicators of the kinds of intelligence required to cooperate. To classify how the different tasks are performed, we (Boesch and Boesch 1989) proposed operational definitions of cooperative tasks. In similarity, a group of individuals performs similar actions to accomplish the task, whereas in synchrony, individuals coordinate their actions in time. A further complication is apparent in coordination, when the actions are coordinated not only in time but also in space, as is seen when wild dogs hunt a zebra by fanning behind the prey and chasing it from different directions. Collaboration occurs when the individuals perform different but complementary roles to achieve the task. A group action occurs when at least two individuals act together, and in those situations the individuals must to some extent consider what the others are doing. Collaboration requires the further elaboration of individuals understanding one another since in this case they performed different roles that are only possible if each considers the others' actions. Thus, in cooperation it is necessary to consider the perspectives of others.

In captivity, chimpanzees have successfully passed tests in which they needed to coordinate their actions (Chalmeau 1994) and were obliged to collaborate (Savage-Rumbaugh et al. 1978). Similarly, orangutans successfully performed such coordinating tasks, whereas capuchin monkeys succeeded only rarely, and macaques and baboons failed (Chalmeau et al. 1997). After a closer look it became apparent that capuchins learned the test individually but performed it so frequently that if two of them did it 
at the same time they were successful, but they never understood the social dimension of the task and were never seen to wait specifically for a partner nor to synchronize their action with that of the other. This, plus the comprehension that one's own action is successful only thanks to the joint action of another, is what is required for cooperation.

In this article I address the following two questions: When do chimpanzees cooperate in hunting? How do the different individuals of the community perform a cooperative hunt?

\section{THE CHALLENGE OF HUNTING ARBOREAL PREY}

Chimpanzees' main prey is the red colobus monkey. This species spends most of its time 40-50 $\mathrm{m}$ up in the highest trees of the forest and weighs about 8 to $13 \mathrm{~kg}$ as an adult. Red colobus monkeys rely on their agility in moving and jumping between trees to escape from hunters. Chimpanzee hunters are four to five times heavier than adult colobus monkeys, so a colobus monkey can sit on a branch too thin to support a chimpanzee. Chimpanzees have been observed to overcome this disadvantage in two ways. The first is by hunting for red colobus monkeys in areas where the forest canopy is interrupted or irregular, so that by chasing the monkeys in the appropriate direction they have a fair chance of cornering them, at which point the likelihood of a capture increases. This seems to be the main solution adopted by chimpanzees in Gombe and Mahale National Parks in Tanzania, as well as among the chimpanzees of the Kibale forest in Uganda (Goodall 1986; Mitani and Watts 1999; Nishida et al. 1983; Takahata et al. 1984; Uehara et al. 1992).

The second solution is to hunt in groups as a coordinated team so that even in a forest with a continuous canopy the hunters can corner the prey. This is regularly observed among the chimpanzees of the Taï Forest, Côte d'Ivoire (Boesch 1994b; Boesch and Boesch-Achermann 2000), and it requires the hunters to coordinate their actions precisely. The solution adopted by the hunters is apparently affected by habitat. The more continuous the forest cover, the more difficult it will be to corner an arboreal prey and the more hunters will be obliged to coordinate their actions. Thus, hunting in trees is complicated both by the fact that the prey has different physical abilities than the hunters and by the fact that it reacts not only to the movement of one hunter but also to those of other hunters. In both cases, hunters can increase their chance of success if they are able to predict the reaction of the prey.

Hunting has been observed in all known chimpanzee populations throughout Africa (Kuroda et al. 1996; McGrew 1992). Notwithstanding the general interest of the chimpanzees in capturing mammalian prey and 
eating meat, many important differences have been observed between populations. At Taï, half of the red colobus monkeys captured were adults (Boesch and Boesch-Achermann 2000). Of the 24 adult prey captured between 1991 and 1995, 6 were males, 15 were females, and 3 could not be sexed. Even more adults were captured when chimpanzees hunted blackand-white colobus monkeys $(60 \%)$, despite the fact that males of this species are bigger than red colobus monkeys and regularly attack the chimpanzee hunters. At Gombe, chimpanzees are afraid of adult colobus monkeys (Boesch 1994a; Goodall 1986; Stanford et al. 1994), and they more frequently captured infants, regularly snatching the baby from its mother's belly without harming her, a behavior we saw only twice at Taï. Chimpanzees at Mahale and Ngogo (one of the communities within the Kibale forest) also appear to prefer to hunt infants (Mitani and Watts 1999; Nishida et al. 1983; Uehara et al. 1992). This specialization in infant prey seems to be reflected in the different propensity of hunters to act in groups.

The term "hunter" is used only for individuals that actively take part in a hunt by placing themselves in positions where they could perform a capture, in the case of colobus hunts mostly by climbing to the height where prey are or are expected to be (Boesch and Boesch 1989). In contrast, some authors classify party members that are with hunters as hunters on the basis that they are looking at what is happening (Teleki 1973), others merely on their passive presence (Stanford et al. 1994). The expectation that the number of hunters correlates with the number of individuals in the party (Stanford 1998; Stanford et al. 1994) was not supported in Taï chimpanzees (Boesch 1994b). In the current discussion individuals present during a hunt but not actively taking part are considered "bystanders" and not hunters. During a single hunt an individual may shift from being a bystander to a hunter and vice-versa. Therefore, it is important to follow the contribution of each individual precisely. Under some conditions it might be difficult to distinguish between the two roles (Mitani et al. in press; Scheel and Packer 1991); however, for a topic as complex as cooperative hunting it is important to remain clear about the contribution of each individual. My comparisons are limited to the Gombe, Mahale, and Taï populations, for which detailed and comparable observations on hunting behavior are available.

The tendency to hunt in groups and to collaborate when hunting in groups varies greatly between the populations, with both being most prevalent at Taï (Table 1). I have shown previously that in Taï chimpanzees group hunting pays off, as individual hunters receive more meat than bystanders and receive the most meat when three to five hunters have been working together (Boesch 1994b). Among the Gombe chimpanzees, bystanders are as successful in receiving meat as hunters, and therefore it does not pay to join a group hunt in this population (Boesch 1994b). 
Table 1. Group-hunting in Taï, Gombe, and Mahale

Chimpanzees. Each hunt is tabulated at the

highest level of organization observed

\begin{tabular}{lccrrrr}
\hline & \multicolumn{3}{c}{ Solitary Hunts } & \multicolumn{2}{c}{ Group Hunts } & \multicolumn{2}{c}{ Collaboration } \\
\hline Taï & 52 & $16 \%$ & 274 & $84 \%$ & 211 & $77 \%$ \\
Gombe & 55 & $64 \%$ & 31 & $36 \%$ & 6 & $19 \%$ \\
Mahale & 14 & $28 \%$ & 37 & $72 \%$ & 0 & $0 \%$ \\
\hline
\end{tabular}

Mahale: Takahata et al. 1984, Uehara et al. 1992

Gombe: Includes two years of red colobus hunts (Busse 1978)

and one year of baboon hunts (Teleki 1973)

Gombe chimpanzees are very efficient hunters, and lone hunters at Gombe capture red colobus monkeys more than five times more quickly than lone hunters at Taï (Boesch 1994b; Boesch and Boesch-Achermann 2000). Taï chimpanzees capture heavier prey, but this does not fully compensate for the longer time needed to achieve a capture, and the chimpanzees at Gombe gain more per minute expended than those at Taï. Gombe chimpanzees' hunting success is due to the fact that lone hunters realize a capture every second hunting attempt within less than 4 minutes. Obviously, it is difficult to improve on such success, and there is no pressure for the Gombe chimpanzees to hunt more in groups. The differences in success reflect the conditions in which the chimpanzees hunt: at Taï, red colobus are in emergent trees over $40-50 \mathrm{~m}$ high and have a good chance of avoiding chimpanzees. In contrast, the canopy is lower in the woodland-savanna at Gombe, and the trees are only about $15 \mathrm{~m}$ high and offer limited possibilities for escape, so the costs of pursuit are much lower (Boesch 1994b).

\section{TAÏ CHIMPANZEES' HUNTING ROLES}

In most hunts, the chimpanzees surprise the prey by approaching soundlessly, remaining on the ground beneath them, scrutinizing the vegetation for monkeys, and concentrating their attention on those prey groups that are most numerous and lowest in the trees before starting to climb. When the prey are really low in the trees, some of the chimpanzees may rush up in an attempt to catch one by surprise, which is rarely successful. Otherwise, one of them slowly climbs to a height of about $5 \mathrm{~m}$, usually unnoticed by the colobus (a second chimpanzee may climb another tree in coordination with the first one, but this is rare). The others move on the ground in anticipation of the possible escape routes of the colobus and ready themselves to join the pursuit. When the climber has been spotted 
by the monkeys, he rushes up, and they begin to move. The hunter's contribution then consists mainly of keeping them moving in a certain direction while the others follow on the ground and undertake different blocking moves. The driver usually follows the monkeys in the branches without trying to capture one on his own. Thus, a driver is a hunter following the prey in a given direction without trying to catch up with them.

At this stage the colobus are usually still in a large group. The chimpanzees try to keep them moving in one direction, and if they try to escape in two or more directions, a chimpanzee may climb up to block an escape route. Thus, a blocker is a hunter placing himself in a tree so as to block the progression of the prey. As the hunt progresses, some take turns in performing the driver role by climbing trees under the escaping colobus, while others assume a chaser role, attempting to catch a monkey by a rapid pursuit. Thus, a chaser is a hunter moving quickly after the prey, trying his best to catch up with one. The chimpanzees usually select and try to isolate an individual, often a mother with her baby, or a small group of individuals. Once they are separated from the main group, the hunt accelerates with chasers climbing different trees along the escape route. But the most difficult task remains to be done, requiring a hunter to anticipate the location of the tree to which the targeted colobus are going to flee, and to be there before the first monkey arrives. The chimpanzees that have chased the monkeys up to now have little chance to achieve a capture themselves via straight pursuit in the emergent trees. The ambusher is the hunter that anticipates the escape route of the quarry long enough in advance to be able either to force it to turn backwards towards its pursuers or to move it downwards into the lower canopy, where chimpanzees have a very good chance of catching it, because in the continuous tree cover at this level chimpanzees move faster than colobus monkeys. Thus, an ambusher is a hunter placing himself in a position where no prey is yet and where he cannot be easily seen, and he will rush toward the prey as soon as it enters his tree.

This "ideal" hunt reaches its conclusion through complete involvement of all hunters, but at any moment during such a hunt a capture may occur. We call such hunts "collaborative," and as we have seen in Table 1, they represent $77 \%$ of all the hunts observed among Taï chimpanzees.

The hunting roles described here vary in how much is required in terms of understanding prey movement: a driver only needs to follow the prey from a distance, not a cognitively demanding action. A chaser, who also follows the prey, has to adapt his speed to catch up with it, which requires further judgment of speed and distance. A blocker or an ambusher has to position himself where he expects the prey to arrive, and this requires anticipation of the prey's reactions. Anticipation is further complicated by the fact that the hunter not only has to anticipate the direction in which the prey will flee (recorded as a half anticipation), but also the speed of the prey 
so as to synchronize his movements to reach the correct height in the tree before the prey enters it (recorded as a full anticipation). This is more complex than it sounds as the hunt happens in three-dimensional space, and the hunter has to convert the speed of the prey into the distance he has to run ahead, mostly out of sight on the ground, and judge the time he will need to climb a tree high enough to be able to lay an ambush unnoticed by the monkey. To distinguish between half and full anticipation is rather easy, for a chimpanzee that makes half an anticipation typically waits for the colobus to confirm his prediction by staying at the base of the tree until the monkey reaches it and then rushes up as quickly as possible. Those making a full anticipation climb into the tree before any colobus enters it. We also recorded a double anticipation in which a hunter anticipates not only the actions of the prey, but also the effect the action of other chimpanzees will have on the future movements of the colobus-in other words, he does not anticipate what he sees (the escaping colobus) but how a future movement of another hunter will further influence the escaping monkeys. We saw only eight moves of double anticipation, and Brutus made five of them. However, we probably underestimated the frequency of double anticipations, for the observation conditions prevailing during the hunts usually made it difficult to determine whether or not the conditions for double anticipation were fulfilled.

Figure 1 presents the hunting roles used by the males during 248 hunts observed from 1987 to 1995 . During these hunts, the hunters were observed to perform 1,402 hunting movements with an average number of 108 per male. Some hunters performed up to 5 or 6 movements during the same hunt, while others made just one. Some performed different roles

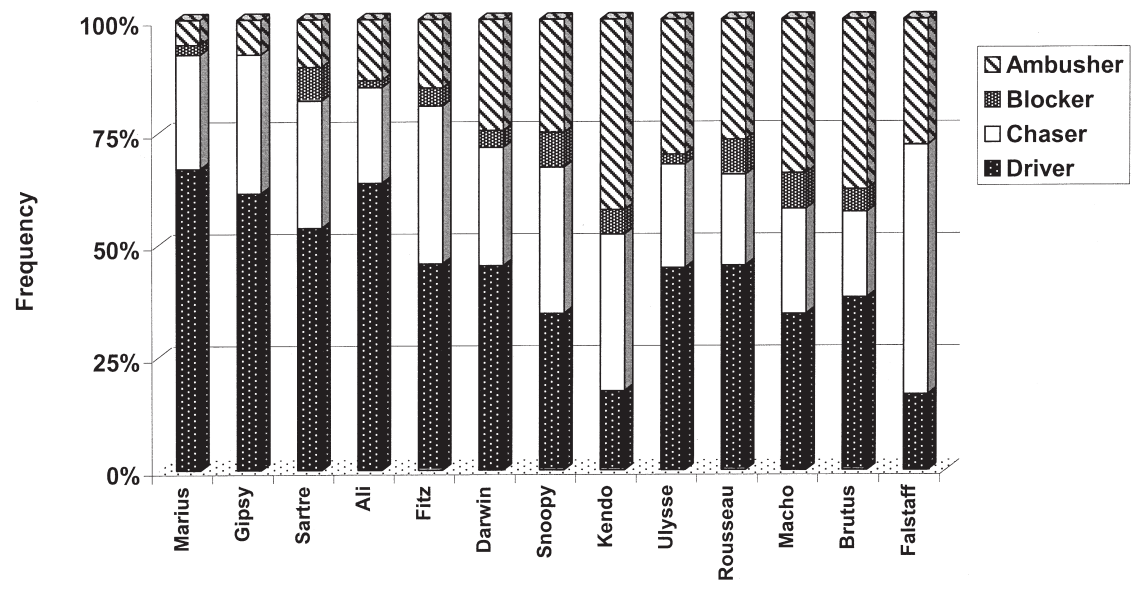

Figure 1. Roles performed during hunts by Taï chimpanzee males. 
during the same hunts, while others regularly performed the same roles. As can be seen in the figure, all hunters performed all four roles, and we cannot claim that there is a rigid specialization among them. The driver role was the most commonly used, representing $40 \%$ of all hunting movements observed, followed by chaser movements (27\%) and ambushing movements (21\%). Important differences are apparent in the frequency of performance of the different roles by the hunters (Figure 1). A closer analysis reveals that the performance of the chaser and blocker role was independent of the age of the hunter, whereas both driver and ambusher roles were strongly age dependent. This leads to the question of how these roles were learned by the hunters.

\section{LEARNING OF HUNTING ROLES BY TAÏ CHIMPANZEES}

The propensity of hunters to perform complex roles and use different levels of anticipation was analyzed to reveal how hunting roles were learned. Chimpanzee hunting behavior typically develops late. We observed youngsters to be attracted to hunting, and we regularly saw very young chimpanzees climb towards groups of colobus monkeys while their mothers rested. At 6 to 8 years old they started to approach the colobus, but when close were invariably chased by adult monkeys, and they ran away screaming with fear. Some reckless ones approached again and again, and this mock chase between young chimpanzees and adult colobus could last for up to half an hour. We did not count such interactions as hunts, and they are not analyzed here. At 8 years of age, some young males progressively mastered their fear, did not scream when threatened, and started to chase small colobus, but still ran away quickly when attacked by adult males. In the real hunting context, when the adult chimpanzee males were active, these youngsters contributed progressively to the hunts by eliciting flight movements within the colobus. Such participations of the four youngest males in a hunt are included in the analysis. At around 10 years of age chimpanzees started to hunt more efficiently. They were less afraid of the colobus and became effective drivers; for example, Marius drove prey in $70 \%$ of his contributions and Ali did so in $60 \%$ of his.

Learning hunting behavior is a long process, as performing the most complex roles well requires 20 years of observation and practice. Because of small sample sizes, in Figures 2 and 3 all the observations for the 7-year period are pooled and the individual hunters are classified according to their age at the beginning of the observation period in 1987. Young males are keen to hunt, and there was even a tendency for young males to perform more movements per hunt than the older ones $\left(r_{\mathrm{s}}=0.51, N=13, p=\right.$ 0.07). The proportion of ambushes and blocks performed by individual males correlates strongly with age (Figure 2). Older males performed such 


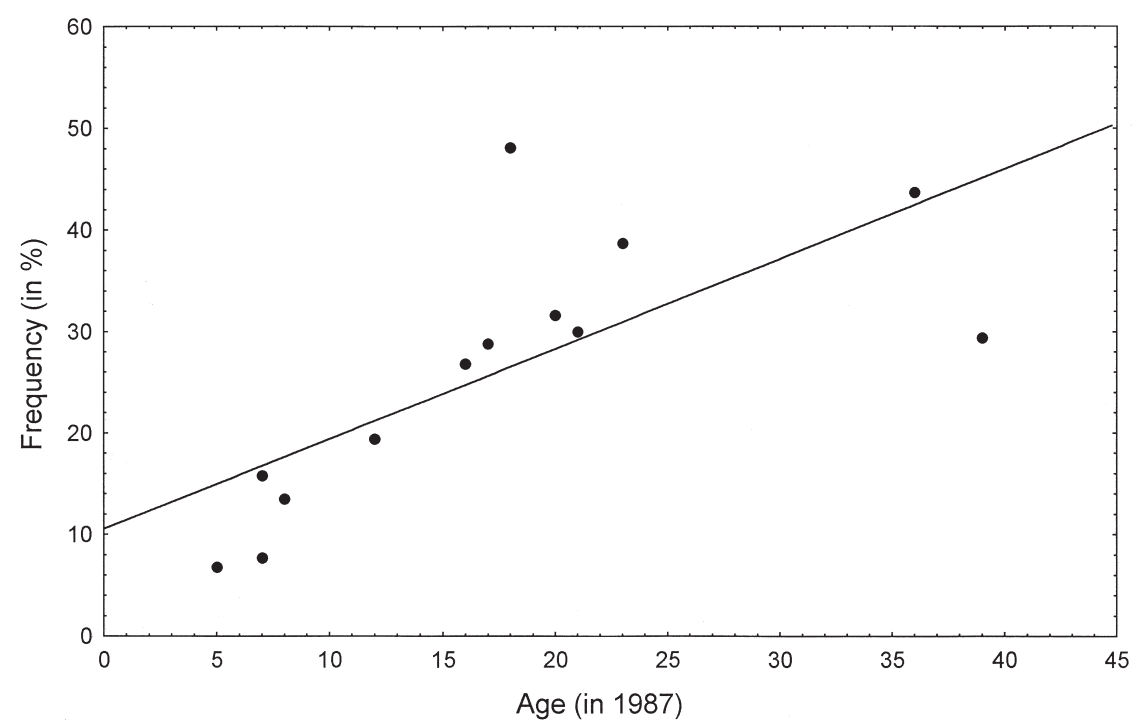

Figure 2. Frequency of ambushes used by hunters of different ages from 1987 to 1995 in Taï chimpanzees $\left(r_{s}=0.85, N=13, p<0.001\right)$.

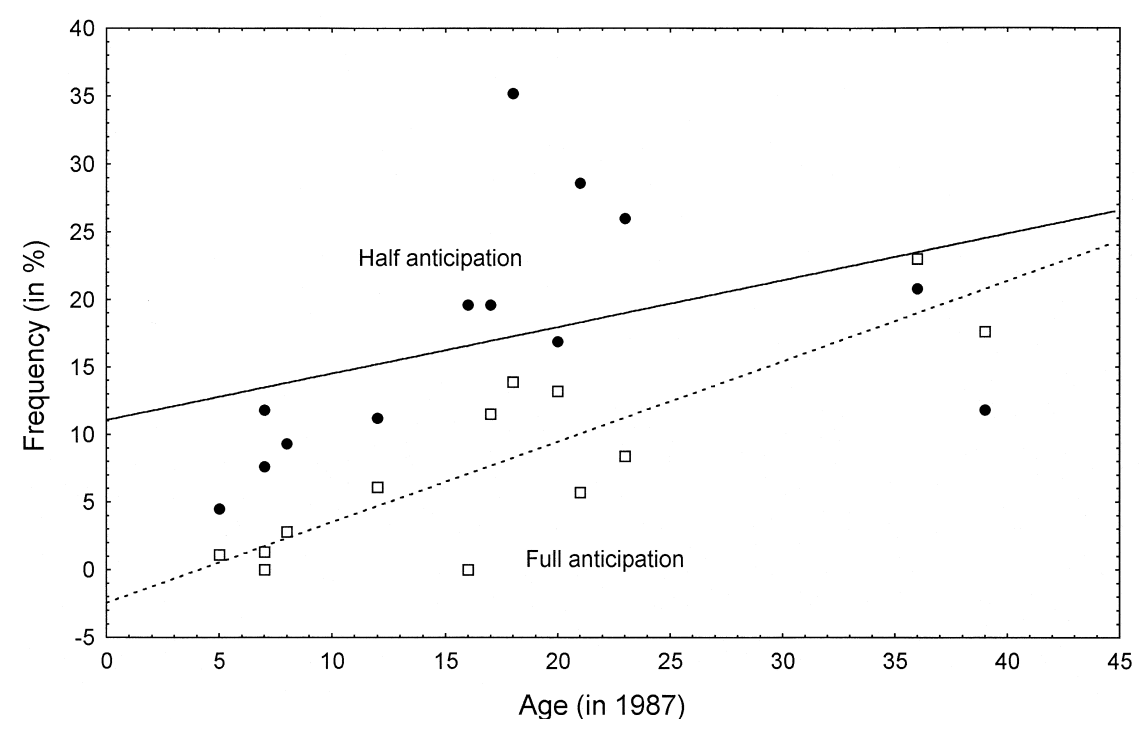

Figure 3. Frequency of anticipations used by hunters of different ages from 1987 to 1995 in Taï chimpanzees (half: $r_{s}=0.76, N=13, p<0.02$; full: $r_{s}=0.82$, $N=13, p<0.001$ ). 
demanding roles three to four times more frequently than the young ones. The correlation with age is equally strong for the anticipations. Half anticipations were used quite early, and their frequency increased among older adolescents and then rose quickly, with 18-year-old males performing half anticipations most frequently. The two oldest males used fewer of them, because when they anticipated, they did so fully. The frequency of full anticipations also increased steadily with age, and only the oldest males (over 30 years) used them frequently (Figure 3). It is striking that only males over 30 years old routinely performed full anticipations. Twentyyear-old males did them as well but occasionally made errors in these situations, either by selecting trees to which no colobus were coming or by changing their mind and climbing more than one tree during the same move. Long-distance anticipations, in which the hunter chose a tree far ahead of the colobus, were seen only in older males, and they, unlike younger ones, did not look constantly at the colobus. Similarly, only the two oldest hunters performed double anticipations.

Thus, the learning of hunting behavior is an exceptionally slow process, for it only starts when the young males are 9 to 10 years old and then continues for about 20 years. Three aspects of hunting might contribute to making this learning process so long. First, the mother is not the model for hunting and an individual can survive without meat. These peculiarities apply, however, to other social behavior patterns and do not explain the 20 -year-long apprenticeship. Second, collaborative hunting requires of the hunter a complex understanding of another species, as well as the coordination of his own actions with those of other hunters. This might well explain the lengthy learning process. Not only do the young hunters have to overcome their fear of the colobus, which may not be easy, if we consider the general fear of adult red colobus seen in all chimpanzee populations, they have to realize that colobus monkeys have different physical possibilities and reactions than they themselves. Fifteen- to 20-year-old chimpanzees, as seen in all studied chimpanzee populations, apparently understand these aspects of the hunts. The most demanding aspect of collaborative hunting is to coordinate actions both in time and in space with those of other hunters. Predicting the reaction of another chimpanzee and its influence on the action of another species is a demanding task, and it is not a surprise that only a few individuals are able to do it (see Boesch and Boesch-Achermann 2000). Note that 20- to 25-year-old chimpanzees are still uncertain about their predictions (performing mainly half anticipations), and that fully grown males are still learning these elaborate roles.

Is the learning of hunting similar in other chimpanzee populations? At Gombe, in 1992, Frodo was 17 years old and by far the best hunter of the community. He was involved in all three collaborative hunts I saw, performing the driver role in each. In two of those hunts, his oldest brother 
Freud, 22 years old, was apparently trying to predict the colobus' reactions and made half anticipations. In the last hunt witnessed, Evered, 40 years old, made a clear full anticipation of the colobus' reaction. This suggests that learning of the hunting behavior at Gombe may follow the same time course as at Taï.

Our estimates of the learning abilities of the chimpanzee are extended by these observations on hunting. Similar analysis of nut cracking by Taï chimpanzees, which involves elaborate use of a hammer, shows that it takes 5 to 7 years to learn (Boesch and Boesch-Achermann 2000). In comparison, learning to hunt starts late, at about 10 years, and shows a long apprenticeship of about 20 years. The classical idea of adult animals not being capable of learning is questioned by these observations. Not only do 25-year-old chimpanzees still learn about hunting, what they do learn is remarkably complex. Human learning of hunting behavior has been followed in details in two hunter-gatherer societies, the Ache from Paraguay and the Hiwi from Venezuela (Kaplan et al. 2000), and it shows surprising similarities with the Taï observations: young men start to hunt at about 15 years of age, and meat production by men peaks at around 35 years. This suggests a comparable learning process of 20 years, as in chimpanzees.

\section{THE BENEFIT OF THE DIFFERENT HUNTING ROLES}

Not all chimpanzees present at a kill site have access to meat. Competition is high between hunters and non-hunters, and participation in the hunt is the key factor that affects meat access: hunters receive more meat than non-hunting males (Boesch 1994b). In the current analysis, meat access was analyzed by taking into account the different contributions of each group member during the hunt. Six factors that might be important during a hunt are considered: the average time an individual has been seen to take active part in a hunt; the average number of hunting moves; whether he made a capture or not; the number of ambush moves performed by the hunter; the level of his anticipations; and the number of hunters taking part in the hunt. We found two strong correlations (Table 2): the more moves a hunter performed, the more time he spent hunting. The more a chimpanzee tried to ambush the prey, the more he anticipated the escape movements of the prey. The other factors did not correlate. There seems to be no easy way for individual hunters to assure themselves a capture. Hunting longer did not guarantee an individual more captures, nor did the more demanding roles, such as anticipating prey movements and ambushing, increase the likelihood of achieving a capture. Hunting is a collective undertaking, and an ambush can increase the likelihood of a capture only if the other roles are simultaneously fulfilled. Were this not 
Table 2. Correlations between Six Characteristics of Roles Observed in Hunters among Taï Chimpanzees between 1986 and 1995: hunting time of a hunter, number of his moves, whether he made a capture or not, number of his ambushes, level of his anticipations, and number of hunters taking part in the hunt

\begin{tabular}{lrrrrr}
\hline & Time & Move & Capture & Ambush & Anticipate \\
\hline Move & $0.695^{*}$ & & & & \\
Capture & -0.107 & -0.087 & & & \\
Ambush & 0.097 & 0.316 & -0.024 & & \\
Anticipate & 0.064 & 0.252 & -0.004 & $0.734^{*}$ & \\
Number of hunters & 0.258 & 0.105 & -0.230 & 0.098 & 0.054 \\
\hline
\end{tabular}

* To account for multiple comparisons, we considered only cases where $p<0.01$.

Table 3. Meat Intake of Hunters for Successful Hunts According to the Role Performed

\begin{tabular}{lccc}
\hline Roles & Number & $\begin{array}{c}\text { Amount of meat eaten } \\
\text { (time eating measured } \\
\text { by minutes spent eating) }\end{array}$ & $\begin{array}{c}\text { Amount of meat } \\
\text { secured (time eating } \\
\text { + time sharing) }\end{array}$ \\
\hline $\begin{array}{l}\text { Bystander } \\
\text { Captor }\end{array}$ & 314 & 27.8 & 32.2 \\
Driver / Chaser & 139 & 58.6 & 85.4 \\
Ambush & 181 & 24.2 & 31.5 \\
$\quad$ Half anticipation & 86 & 27.3 & 35.5 \\
$\quad$ Single anticipation & 70 & 44.8 & 61.8 \\
$\quad$ Double anticipation & 17 & 54.3 & 84.8 \\
\hline Factor & $\mathrm{df}$ & F-value & P-value \\
\hline Captor & 1 & 17.57 & 0.0000 \\
Ambush & 1 & 14.04 & 0.0002 \\
Number of hunters & 1 & 4.60 & 0.01 \\
\hline
\end{tabular}

Results of an analysis of variance considering factors affecting meat intake, taking interactions into account (Procedure GLM, SAS 1985). Only significant results $(p<0.05)$ are shown. * "Time eating" measures the time a meat owner takes to eat his meat, while "time eating + time sharing" measures the time a meat owner eats meat and the time others take to eat the meat they received from the meat owner.

${ }^{+}$Drivers, chasers, and ambushes that succeed in capturing a prey were pooled in the captor category.

the case, the chance of a capture for a given hunt would not increase however well the ambushing was done.

Table 3 shows that meat access for an individual per successful hunt is significantly affected by several factors. The number of hunters reduced the amount of meat eaten per successful hunt, as the number of meat eaters increased with the number of hunters $(p<0.001)$. The three factors 
that improved meat access were being the captor, ambushing the prey, and anticipating prey movements. Of these three, being the captor was most important, but the other two roles were also significantly rewarded. In Table 3, the data presented for the different roles include only those performed without successfully making a capture; otherwise they have been pooled in the captor category. Both ambushing and anticipating the prey movements enabled the hunters to prevent their prey from escaping; in most cases they bring hunters close to the prey, a basic condition for a capture. Thus, certain roles during the hunt were valued more highly by group members than others, and those who performed these roles were allowed access to more meat. This indicates that group members monitor what other individuals are doing during a hunt and can assess the contribution of each hunter. This is intriguing because, as we have seen earlier, some of the anticipation roles are very demanding, and most group members seem unable to perform them but nevertheless value them highly.

These meat-sharing rules strongly restrict the possibility of cheating. Individuals pretending to hunt or hunting by performing less demanding roles, or moving in trees without aiming at a prey, received less meat than other hunters. Thus untalented adult hunters are penalized. It also penalizes young chimpanzees that may be keen to hunt but have yet to learn how to do the right thing at the right time-hunting time was not correlated with meat access, and youngsters often hunted for longer periods of time than prime males. Individuals pretending to hunt did not gain access to much meat, as ambushing or achieving a capture were the two roles most likely to result in access to meat. An individual needed to perform the roles that directly resulted in hunting success to acquire meat. The precision of these sharing rules suggests that cheating is a real problem in chimpanzees, but its importance is hidden because the meat-sharing rules keep cheating rare.

As stated above, although youngsters regularly hunted for long periods of time, performing the less demanding roles (driving or chasing prey), they gained limited access to meat. In contrast, an adult that hunted for a short time by ambushing gained much more meat. Simply driving prey was rarely successful, but efficient ambushing often led to a capture. The Taï meat-sharing rules acknowledge this role of ambusher and stabilize cooperation by guaranteeing both more meat to hunters than to the others and more meat to hunters making important contributions than to those performing the less decisive roles.

\section{DISCUSSION}

Group hunting is common in Taï chimpanzees and performed by individuals of different ages. As expected under the mutualistic approach of co- 
operation, individual hunters profit from this cooperative action by gaining access to more meat than they would if they had hunted on their own. We expanded this approach by looking at the meat-sharing rules and showed it is not the fact of hunting per se that is important; time spent hunting does not predict the success of individual hunters. More important is the real contribution to the outcome made by the individual hunter. Capturing the prey guarantees the highest reward, while ambushing and anticipating the prey movements, which often are necessary contributions, are highly rewarded as well. Performing other, less decisive roles does not increase meat access. Therefore, individual effort is not directly rewarded, but some specific participation, leading to a successful hunt, is required for the individual to have increased access to meat. These rules are socially enforced and illustrate the complexity of the cooperative action. In this conditional, mutualistic situation, hunters gain from taking an active part in the hunt, and more so by performing actions judged by group members to increase the likelihood of a capture.

Alternative explanations might be proposed for these results. For example, perhaps capturers and ambushers gain more meat simply because they are closest to the captured prey and thus have more time to eat meat. Similarly, it could be suggested that older individuals who perform more ambushing roles are dominant and therefore prevent others from performing such roles. These explanations might seem likely among Gombe and Mahale chimpanzees where dominant individuals regularly steal monkey prey away from capturers (Goodall 1986; Nishida et al. 1992). However, at Taï, dominant individuals steal prey very rarely (Boesch and Boesch 1989), and dominant individuals obtain less meat than hunters (Boesch 1994b). Also, I never observed individuals competing for the best position in trees so as to be able to perform an ambush. In fact, in Taï, immediately following a capture, the capturer usually makes a "capture call" that attracts most chimpanzees within auditory distance. During the first minutes following a capture the excitement in the forest is very high and barely any meat is eaten. All the chimpanzees present scream at the top of their lungs and concentrate around the capturer and its prey. Only once they have calmed down do the chimpanzees begin sharing and eating their meat.

In other chimpanzee populations, group hunting varies from being uncommon in Tanzania (Gombe: Goodall 1986; Mahale: Nishida et al. 1983) to common in the large community of the Ngogo chimpanzees (Watts and Mitani 1999). Evaluation of the individual benefits under varying hunting group sizes in Gombe chimpanzees showed that meat access was not dependant on the individual contribution during the hunt (Boesch 1994b). Meat sharing seems to favor either the owner's allies (Mahale chimpanzees: Nishida et al. 1992) or the higher-ranking males (Ngogo chimpanzees: Mitani and Watts 1999). Similarly, among social carnivores, group 
hunting is often observed when conditions are difficult, such as in lowprey-density habitats, but direct measures of meat intake at the individual level are still awaited (Caro 1994; Creel 1997; Creel and Creel 1995; Packer and Caro 1997; Packer et al. 1990).

Individual hunters need to take into account what other hunters do and what effect their actions will have on the escape movements of the prey. As noted above, red colobus monkeys possess different physical properties and perceive and react to danger in a different way than chimpanzees. Only by taking into account such different perspectives can a hunter predict where and when a red colobus may reach a given tree. In the 262 anticipations we observed, only $4(1.5 \%)$ were erroneous in the sense that hunters selected trees to which the colobus could not or did not come. Thus, in $98 \%$ of the anticipations, the hunters anticipated the prey movements correctly. This supports the hypothesis that chimpanzees correctly attribute abilities to other species and use this to predict their behavior. However, only a moderate proportion of the anticipatory movements were performed with full anticipation of the prey's movement (32\% of 262 anticipation movements). If and when the prey is going to reach a specific location is not obvious and requires accurate prediction. In addition, this prediction is conditioned by the actions of other hunters; if, for example, the driver changes his direction, the prey will adjust their movements as well. Hence, performance of the ambush role requires social knowledge of what other hunters see and are able to do, as well as knowledge of the specific way they are going to react to this knowledge (Boesch and BoeschAchermann 2000). Recent studies have partly confirmed such findings with captive chimpanzees (Hare et al. 2000, 2001; Whitten 2000).

Chimpanzees show extended learning abilities enabling them to acquire knowledge of the most complex hunting roles over a period of up to 20 years. The length of this learning process seems to be related to the demanding cognitive abilities required to perform them (Boesch and BoeschAchermann 2000). These observations reveal the complexity of foraging and social strategies and highlight the importance of studying natural behaviors when the question deals with animals' cognitive capacities.

It has been proposed that the human diet is strongly affected by the cooperative actions of others, whereas chimpanzee food consumption is purely the result of individual foraging effort (Kaplan et al. 2000; Hill 2002). Our observations on the Taï chimpanzees show clearly that this does not apply to all populations: forest chimpanzees seem to hunt as a rule in groups (Boesch and Boesch-Achermann 2000; Mitani and Watts 1999), and the important meat consumption in these populations is dependant on the foraging effort of cooperative teams. Similarly, during the long apprenticeship of nut cracking in some West African chimpanzee populations, the youngsters are for 6 to 8 years fully dependent on their mothers for their important daily nut intake (Boesch and Boesch-Achermann 2000). Thus, 
for two of their richest foods, chimpanzees are strongly dependent on the cooperative effort of other individuals, as has been shown in some huntergatherer societies.

I thank the Ministry of Scientific Research and the Ministry of National Parks for supporting the Taï chimpanzee project for all those years, and especially the Projet Autonome de Conservation du Parc National de Taï (PACPNT), the Centre Suisse de Recherches Scientifiques (CSRS), and the Centre de Recherche en Écologie (CRE). This project has been financially supported by the Swiss National Science Foundation and the Max Planck Society. I thank Hedwige Boesch, Steve Stearns, Duri Rungger, Toshisada Nishida, William McGrew, and two anonymous reviewers for commenting on the manuscript.

Christophe Boesch is director of the department of primatology in the Max Planck Institute of Evolutionary Anthropology, and a professor at the University of Leipzig. He has studied wild chimpanzees since 1979, mainly in Taï National Park, Côte d'Ivoire, and his main interests are in the evolution of tool use, hunting, and animal culture, as well as documenting reproductive strategies of both sexes and social structure in great apes.

\section{REFERENCES}

Axelrod, R., and W. D. Hamilton

1981 The Evolution of Cooperation. Science 211:1390-1396.

Boesch, C.

1994a Chimpanzees-Red Colobus: A Predator-Prey System. Animal Behaviour 47:1135-1148.

1994b Cooperative Hunting in Wild Chimpanzees. Animal Behaviour 48:653667.

Boesch, C., and H. Boesch

1989 Hunting Behavior of Wild Chimpanzees in the Taï National Park. American Journal of Physical Anthropology 78:547-573.

Boesch, C., and H. Boesch-Achermann

2000 The Chimpanzees of the Taï Forest: Behavioural Ecology and Evolution. Oxford: Oxford University Press.

Busse, $C$.

1978 Do Chimpanzees Hunt Cooperatively? American Naturalist 112:767770.

Caro, T. M.

1994 Cheetahs of the Serengeti Plains: Group Living in an Asocial Species. Chicago: University of Chicago Press.

Chalmeau, R.

1994 Do Chimpanzees Cooperate in a Learning Task? Primates 35:385-392.

Chalmeau, R., E. Visalberghi, and A. Gallo

1997 Capuchin Monkeys, Cebus apella, Fail to Understand a Cooperative Task. Animal Behaviour 54:1215-1225. 
Clements, K., and D. Stephens

1995 Testing Models of Non-kin Cooperation: Mutualism and the Prisoner's

Dilemma. Animal Behaviour 50:527-535.

Cooper, S. M.

1991 Optimal Hunting Group Size: The Need for Lions to Defend Their Kills Against Loss to Spotted Hyenas. African Journal of Ecology 29:130-136.

Creel, S.

1997 Cooperative Hunting and Group Size: Assumptions and Currencies. Animal Behaviour 54:1319-1324.

Creel, S., and N. M. Creel

1995 Communal Hunting and Pack Size in African Wild Dogs, Lycaon pictus. Animal Behaviour 50:1325-1339.

Dugatkin, L.

1997 Cooperation among Animals: An Evolutionary Perspective. Oxford: Oxford University Press.

Estes, R. D., and J. Goddard

1967 Prey Selection and Hunting Behavior of the African Wild Dog. Journal of Wildlife Management 31:52-70.

Fanshawe, J. H., and C. D. Fitzgibbon

1993 Factors Influencing the Hunting Success of an African Wild Dog Pack. Animal Behaviour 45:479-490.

Goodall, J.

1986 The Chimpanzees of Gombe: Patterns of Behavior. Cambridge: The Belknap Press of Havard University Press.

Hamilton, W. D.

1964 The Genetical Theory of Social Behavior (I and II). Journal of Theoretical Biology 7:1-32.

Hare, B., J. Call, B. Agnetta, and M. Tomasello

2000 Chimpanzees Know What Conspecifics Do and Do Not See. Animal Behaviour 59(4):771-785.

Hare, B., J. Call, and M. Tomasello

2001 Do Chimpanzees Know What Conspecifics Know? Animal Behaviour 61:139-151.

Hill, Kim

2002 Altruistic Cooperation during Foraging by the Ache, and the Evolved Human Predisposition to Cooperate. Human Nature 13:105-128.

Kaplan, H., K. Hill, J. Lancaster, and A. Hurtado

2000 A Theory of Human Life History Evolution: Diet, Intelligence and Longevity. Evolutionary Anthropology 9:156-185.

Kruuk, H.

1972 The Spotted Hyena. Chicago: University of Chicago Press.

Kuroda, S., S. Suzuki, and T. Nishihara

1996 Preliminary Report on Predatory Behavior and Meat Sharing in Tschego

Chimpanzees (Pan troglodytes troglodytes) in the Ndoki Forest, Northern Congo. Primates 37:253-259.

Maynard Smith, J.

1982 Evolution and the Theory of Games. Cambridge: Cambridge University Press. 
Mech, D. L.

1970 The Wolf. New York: Natural History Press.

McGrew, W.

1992 Chimpanzee Material Culture: Implications for Human Evolution. Cambridge: Cambridge University Press.

Mills, M. G. L.

1990 Kalahari Hyenas: The Comparative Behavioural Ecology of Two Species. London: Chapman and Hall.

Mitani, J., and D. Watts

1999 Demographic Influences on the Hunting Behavior of Chimpanzees. American Journal of Physical Anthropology 109:439-454.

Mitani, J., D. Watts, and J. Lwanga

in press Ecological and Social Correlates of Chimpanzee Party Size and Composition. In Behavioural Diversity in Chimpanzees and Bonobos, C. Boesch, G. Hohmann, and L. Marchant, eds. Cambridge: Cambridge University Press.

Nishida, T., S. Uehara, and R. Nyondo

1983 Predatory Behavior among Wild Chimpanzees of the Mahale Mountains.

Primates 20:1-20.

Nishida, T., T. Hasegawa, H. Hayaki, Y. Takahata, and S. Uehara

1992 Meat-sharing as a Coalition Strategy by an Alpha Male Chimpanzee?

In Human Origins, T. Nishida, W. C. McGrew, P. Marler, M. Pickford, and

F. de Waal, eds. Pp. 159-174. Topics in Primatology, vol. 1.Tokyo: University of Tokyo Press.

Packer, C., and T. Caro

1997 Foraging Costs in Social Carnivores. Animal Behaviour 54:1317-1318.

Packer, C., D. Scheel, and A. E. Pusey

1990 Why Lions Form Groups: Food Is Not Enough. American Naturalist 136: $1-19$.

Savage-Rumbaugh, E. S., D. M. Rumbaugh, and S. Boysen

1978 Linguistically Mediated Tool Use and Exchange by Chimpanzees (Pan troglodytes). Behavioral and Brain Sciences 201:641-644.

Schaller, G. B.

1972 The Serengeti Lion. Chicago: University of Chicago Press.

Scheel, D., and C. Packer

1991 Group Hunting Behaviour of Lions: A Search for Cooperation. Animal Behaviour 41:697-709.

Stander, P. E.

1992 Cooperative Hunting in Lions: The Role of the Individual. Behavioral Ecology and Sociobiology 29:445-454.

Stanford, C.

1998 Chimpanzee and Red Colobus: The Ecology of Predator and Prey. Cambridge: Harvard University Press.

Stanford, C., J. Wallis, H. Matama, and J. Goodall

1994 Patterns of Predation by Chimpanzees on Red Colobus Monkeys in

Gombe National Park, Tanzania, 1982-1991. American Journal of Physical Anthropology 94:213-229.

Strum, S. C.

1981 Processes and Products of Change: Baboon Predatory Behavior at Gilgil, 
Kenya. In Omnivorous Primates: Gathering and Hunting in Human Evolution, R. S. O. Harding and G. Teleki, eds. Pp. 255-302. New York: Columbia University Press.

Takahata, Y., T. Hasegawa, and T. Nishida

1984 Chimpanzee Predation in the Mahale Mountains from August 1979 to May 1982. International Journal of Primatology 5:213-233.

Teleki, G.

1973 The Predatory Behavior of Wild Chimpanzees. Brunswick: Bucknell University Press.

Trivers, R. L.

1971 The Evolution of Reciprocal Altruism. Quarterly Review of Biology 46: 35-57.

Uehara, S., T. Nishida, M. Hamai, T. Hasegawa, H. Hayaki, M. Huffman, K. Kawanaka, S. Kobayashi, J. Mitani, Y. Takahata, H. Takasaki, and T. Tsukahara 1992 Characteristics of Predation by the Chimpanzees in the Mahale Mountains National Park, Tanzania. In Human Origins, T. Nishida, W. C. McGrew, P. Marler, M. Pickford, and F. de Waal, eds. Pp. 143-158. Topics in Primatology, vol. 1. Tokyo: University of Tokyo Press.

Van Orsdol, K. G.

1984 Foraging behaviour and hunting success of lions in Queen Elizabeth National Park, Uganda. African Journal of Ecolology 22:79-99.

Whitten, A.

2000 Chimpanzee Cognition and the Question of Mental Re-representation. In Metarepresentations: A Multidisciplinary Perspective, D. Sperber, ed. Pp. 1-29. Oxford: Oxford University Press. 